University of Nebraska - Lincoln

DigitalCommons@University of Nebraska - Lincoln

April 1996

\title{
Superparamagnetic magnetic force microscopy tips
}

\author{
P.F. Hopkins \\ NIST, Boulder, Colorado \\ John Moreland \\ NIST, Boulder, Colorado \\ S.S. Malhotra \\ University of Nebraska - Lincoln \\ Sy_Hwang Liou \\ University of Nebraska-Lincoln, sliou@unl.edu
}

Follow this and additional works at: https://digitalcommons.unl.edu/physicsliou

Part of the Physics Commons

Hopkins, P.F.; Moreland, John; Malhotra, S.S.; and Liou, Sy_Hwang, "Superparamagnetic magnetic force microscopy tips" (1996). Si-Hwang Liou Publications. 55.

https://digitalcommons.unl.edu/physicsliou/55

This Article is brought to you for free and open access by the Research Papers in Physics and Astronomy at DigitalCommons@University of Nebraska - Lincoln. It has been accepted for inclusion in Si-Hwang Liou Publications by an authorized administrator of DigitalCommons@University of Nebraska - Lincoln. 


\title{
Superparamagnetic magnetic force microscopy tips
}

\author{
P. F. Hopkins ${ }^{\text {a) }}$ and John Moreland \\ NIST, Boulder, Colorado 80303
}

\section{S. S. Malhotra and S. H. Liou \\ Department of Physics and Astronomy, University of Nebraska, Lincoln, Nebraska 68588}

\begin{abstract}
We report on magnetic force microscopy (MFM) images of a thin-film magnetic recording head taken using batch micromachined silicon tips coated with nanocomposite $\mathrm{Fe}_{60}\left(\mathrm{SiO}_{2}\right)_{40}$ and $\mathrm{Fe}_{70}\left(\mathrm{SiO}_{2}\right)_{30}$ films. The small Fe grain size $(<10 \mathrm{~nm})$ and dilute $\mathrm{Fe}$ volume fraction $(0.29-0.4)$ of these granular films produce tip coatings of low remanence and essentially zero coercivity, reduced by the superparamagnetic properties of these films. We have used these tips to obtain MFM images of the write field of the head with high spatial and magnetic-field resolution. In comparison to images taken using commercial $\mathrm{Co}_{85} \mathrm{Cr}_{15}$-coated tips, these MFM images show reduced tip memory effects and clearly delineate the gap field from the pole pieces. (c) 1996 American Institute of Physics. [S0021-8979(96)57108-8]
\end{abstract}

Batch fabrication of silicon micromachined cantilevers with integral tips ${ }^{1,2}$ coated with thin magnetic films has facilitated the emergence of magnetic force microscopy (MFM) as a qualitative high-resolution magnetic imaging tool. ${ }^{3}$ Improvements in magnetic tip coatings are necessary, however, to extend MFM capabilities to imaging stronger stray fields and for quantitative field measurements. Typically, tips coated with $10-50 \mathrm{~nm}$ of a magnetically hard material (such as $\mathrm{Co}_{85} \mathrm{Cr}_{15}$ ) are used for MFM, providing high sensitivity with an assumed tip magnetic moment $\mathbf{m}$ which is fixed in direction and magnitude. ${ }^{2}$ High-resolution imaging of high-coercivity materials and current-biased magnetic recording heads, however, can subject these tips to fields higher than the coercive field $H_{c}$ of the tip coating, ${ }^{2}$ resulting in a time-dependent $\mathbf{m}$ and generating images which are difficult or impossible to interpret.

One alternative is to use tips coated with a ferromagnetically soft material such as $\mathrm{NiFe}^{1,4}$ The tip moment $\mathbf{m}$ is assumed to align with the local stray field $\mathbf{B}$ and have a magnitude equal to the saturated value $m_{s}$. Unfortunately, the shape and small size of the tip can change the domain structure and greatly enhance the coercivity ${ }^{1}$ of these coatings, producing MFM images that also contain artifacts due to hysteresis of the tip moment. To completely eliminate memory effects from MFM images requires tips which have zero hysteresis over the operating field range.

MFM tips coated with granular magnetic films consisting of isolated superparamagnetic particles $(<10 \mathrm{~nm})$ would have zero remanence and coercivity, resulting in images with no tip memory effects. Unlike $\mathrm{NiFe}$ and other ferromagnetic coatings, the magnetic properties of the individual particles in the superparamagnetic films should not be altered by the shape of the tip, for tip radii larger than the particle size. Sensitivity, determined by $\mathbf{m}$, would be orders of magnitude larger than tips coated with paramagnetic films and in strong magnetic fields could approach or exceed that of available ferromagnetic-coated tips. These tips might also be useful for nonperturbative imaging of domain patterns in low coercivity films, ${ }^{5}$ due to the lower stray fields emanating from these

${ }^{\text {a)} C u r r e n t ~ a d d r e s s: ~ Q u a n t u m ~ C o r p ., ~ L o u i s v i l l e, ~ C O, ~ 80028-8188 . ~}$ tips. ${ }^{1}$ In contrast to the assumed fixed moment $\mathbf{m}$ of the ferromagnetic-coated tips, $\mathbf{m}$ of the superparamagnetic tips can increase with field. This results in a shorter range tipsample force $\mathbf{F}=\boldsymbol{\nabla}(\mathbf{m} \cdot \mathbf{B})$. In the case of tips of extended geometry where the forces over the tip volume must be summed, ${ }^{3}$ the shorter range force means a smaller tip volume contributes to the signal. This leads to improved resolution providing the tip-sample force yields a sufficient signal-tonoise ratio.

We have coated commercial silicon micromachined MFM cantilevers and tips with granular $\mathrm{Fe}-\left(\mathrm{SiO}_{2}\right)$ films. These nanocomposite films consist of small $\mathrm{Fe}$ crystallites (3-7 nm) in an amorphous $\mathrm{SiO}_{2}$ matrix. ${ }^{6-8}$ By growing films with dilute $\mathrm{Fe}$ volume fractions $p$ of $0.29-0.4$ we have manufactured $\mathrm{Fe}-\left(\mathrm{SiO}_{2}\right)$-coated tips that show no noticeable tip memory effects and which have the following additional advantages for batch MFM tip fabrication: (1) excellent adhesion to silicon; (2) high corrosion resistance and wear resistance; (3) the deposition process can be scaled up for coating entire wafers; and (4) the magnetic properties can be engineered by controlling the film microstructure. ${ }^{6-8}$

Cantilevers with spring constants $k=1-5 \mathrm{~N} / \mathrm{m}$, resonant frequencies $f_{0}=70-89 \mathrm{kHz}$, and quality factors $Q \sim 200$ in air were $\mathrm{rf}$ magnetron sputter-coated at $300 \mathrm{~K}$ using a homogeneously mixed composite $\mathrm{Fe}-\left(\mathrm{SiO}_{2}\right)$ target of the desired composition. ${ }^{8}$ As listed in Table I, one batch of six cantilevers with tips was coated with $40 \mathrm{~nm}( \pm 10 \%)$ of $\mathrm{Fe}_{70}\left(\mathrm{SiO}_{2}\right)_{30}$ and another batch was coated with $40 \mathrm{~nm}$ of $\mathrm{Fe}_{60}\left(\mathrm{SiO}_{2}\right)_{40}$. A third batch of commercial $\mathrm{Co}_{85} \mathrm{Cr}_{15}$-coated tips $^{2}$ was also used in this study. Variations in the Fe atomic percentages are less than 5\%. Scanning electron micrographs of the $\mathrm{Fe}-\left(\mathrm{SiO}_{2}\right)$-coated cantilevers show tip end radii of $50-100 \mathrm{~nm}$.

The magnetic data in Table I were derived from Figs. 1(a) and 1(b), which show the volume magnetization $M$ versus applied field $H$ (in plane) for the three different films. The $\mathrm{Fe}-\left(\mathrm{SiO}_{2}\right)$ data were taken at $300 \mathrm{~K}$ on films simultaneously deposited with the tips on glass coupons; the data were normalized to the saturation magnetization (1714 $\mathrm{kA} / \mathrm{m}$ ) of pure Fe by multiplying by the volume fraction $p$. For the CoCr data, the actual coated cantilever substrate was 
TABLE I. Properties of MFM tip coatings. Listed for the three films are the thickness $t$ and the Fe volume fraction $p$. The measured coercivity $H_{c}$ and remanence $M_{r}$ are from Fig. 1 .

\begin{tabular}{|c|c|c|c|c|c|}
\hline Coating & $\begin{array}{c}t \\
(\mathrm{~nm})\end{array}$ & $p$ & $\begin{array}{c}H_{c} \\
\mathrm{kA} / \mathrm{m}\end{array}$ & $\begin{array}{c}H_{c} \\
(\mathrm{Oe})\end{array}$ & $\begin{array}{c}M_{r} \\
(\mathrm{kA} / \mathrm{m})\end{array}$ \\
\hline $\mathrm{Fe}_{70}\left(\mathrm{SiO}_{2}\right)_{30}$ & 40 & 0.39 & 0.08 & (1) & 4 \\
\hline $\mathrm{Fe}_{60}\left(\mathrm{SiO}_{2}\right)_{40}$ & 40 & 0.29 & 1 & (13) & 6 \\
\hline $\mathrm{Co}_{85} \mathrm{Cr}_{15}$ & 40 & $\cdots$ & 34 & $(430)$ & 300 \\
\hline
\end{tabular}

measured after being saturated in plane with a $160 \mathrm{kA} / \mathrm{m}$ field; the data were normalized to $400 \mathrm{kA} / \mathrm{m}\left(400 \mathrm{emu} / \mathrm{cm}^{3}\right)^{2}$ The instrumentation error for $H_{c}$ is $200 \mathrm{~A} / \mathrm{m}(2 \mathrm{Oe})$. The measured $H_{c}$ and remanence for the $\mathrm{Fe}-\left(\mathrm{SiO}_{2}\right)$ films in Fig. 1(a) are very small but nonzero. The nonzero values probably occur because a small fraction of the Fe forms clusters larger than the superparamagnetic limit. ${ }^{6}$ In the absence of clustering, these films would be completely superparamagnetic. Major and minor hysteresis loops for $\mathrm{CoCr}$ are shown in Fig. 1(b), demonstrating a substantial coercivity and remanence.

Figures 2(a) and 2(b) are $10 \mu \mathrm{m}$ scans of magnetic force derivative $^{3}$ and topography, respectively, of a commercial thin-film inductive magnetic recording head. The images were taken simultaneously as described in Ref. 9 using an $\mathrm{Fe}_{70}\left(\mathrm{SiO}_{2}\right)_{30}$-coated tip and with the head current biased at $10 \mathrm{~mA}$. The cantilever was vibrated at the resonance frequency $f_{0}$ with a $30 \mathrm{~nm}$ root-mean-square (rms) amplitude. Figure 2(a) was scanned with the tip $100 \mathrm{~nm}$ above the air bearing surface (ABS), about twice the designed flying height of the head above the disk. Plotted in Fig. 2(a) is the resonant frequency shift $\Delta f$ of the cantilever, arising from the magnetic force $\mathbf{F}$ between the tip and the write field of the head. For small shifts, $\Delta f$ can be approximated by the expression $\Delta f=-f_{0} F^{\prime} /(2 k)$, where $F^{\prime}$ is the gradient along the tip axis of the axial component of the magnetic force $\mathbf{F} .^{2,3}$ The strongest feature in Fig. 2(a) occurs at the gap between the two NiFe pole pieces where the field $(240-320 \mathrm{kA} / \mathrm{m})$ and its spatial derivatives are the highest, resulting in the strongest attractive tip-sample force and largest decrease in

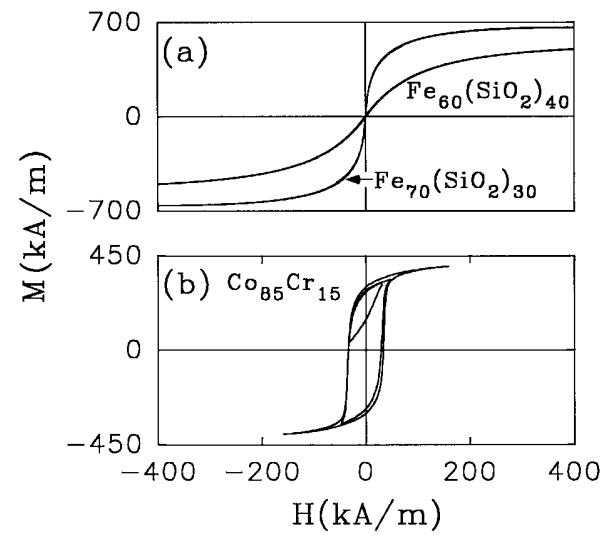

FIG. 1. Magnetization vs applied field $\mathrm{H}$ at $300 \mathrm{~K}$ with $H$ in the plane of the films: (a) 40-nm-thick $\mathrm{Fe}_{70}\left(\mathrm{SiO}_{2}\right)_{30}$ and $\mathrm{Fe}_{60}\left(\mathrm{SiO}_{2}\right)_{40}$ films on glass coupons; (b) commercial cantilever substrate coated with $40 \mathrm{~nm}$ of $\mathrm{Co}_{85} \mathrm{Cr}_{15}$.



FIG. 2. $10 \mu \mathrm{m}$ images of a thin-film inductive magnetic recording head. (a) MFM frequency shift image using a tip coated with $40 \mathrm{~nm}$ of $\mathrm{Fe}_{70}\left(\mathrm{SiO}_{2}\right)_{30}$, a $100 \mathrm{~nm}$ tip-sample spacing, and $10 \mathrm{~mA}$ current bias of the head; (b) simultaneous topographical image showing the leading (P1) and trailing (P2) pole pieces and the $0.2-\mu \mathrm{m}$-wide gap; (c) MFM image, $40 \mathrm{~nm}$ $\mathrm{Fe}_{60}\left(\mathrm{SiO}_{2}\right)_{40}$-coated tip, $10 \mathrm{~mA}$ bias; and (d) MFM image, $40 \mathrm{~nm}$ $\mathrm{Co}_{85} \mathrm{Cr}_{15}$-coated tip, $2 \mathrm{~mA}$ bias. The contrast scales are $50 \mathrm{~Hz}, 50 \mathrm{~nm}, 10$ $\mathrm{Hz}$, and $70 \mathrm{~Hz}$, respectively.

the cantilever resonant frequency. Contrast can also be seen around the edges of the pole pieces where fringing fields are present. There is essentially no frequency shift in the body of the pole pieces. Figure 2(b) is the sample topography and shows polishing scratches across the $0.2-\mu \mathrm{m}$-wide gap and the pole pieces P1 and P2. The contrast between the soft $\mathrm{NiFe}$ poles and the surrounding harder alumina material arises from effects due to the polishing process and magnetic forces affecting the topographical force image.

Figures 2(c) and 2(d) are magnetic images taken with $\mathrm{Fe}_{60}\left(\mathrm{SiO}_{2}\right)_{40}$ and CoCr-coated tips, respectively, under the same imaging conditions as Fig. 2(a). The head was biased at $10 \mathrm{~mA}$ for Fig. 2(c) and $2 \mathrm{~mA}$ for Fig. 2(d). Figure 2(c) is similar to Fig. 2(a) with contrast centered at the gap; however, the signal has dramatically decreased by roughly a factor of 10. Figure 2(d) was taken immediately after magnetizing the $\mathrm{CoCr}$ tip in an external field of $700 \mathrm{kA} / \mathrm{m}$ applied along the tip axis. This image is qualitatively different from Figs. 2(a) and 2(c) because of the substantial coercivity of the $\mathrm{CoCr}$ tip. One pole piece is darker than the other, and near the center of the gap the contrast changes from dark to light. Unlike Figs. 2(a) and 2(c), Fig. 2(d) is not reproducible, and depends on the prior magnetic history of the tip.

Figure 2 can be better understood by looking at individual MFM line traces taken horizontally across the center of the head using the same three tips, with the head biased at different current levels. Each trace pictured in Fig. 3 is an average of at least 40 line scans and shows the resonant frequency shift $\Delta f$ of the cantilever versus position of the tip over the head. The noise in each line scan was approximately $0.2 \mathrm{~Hz} \mathrm{rms}$. The gap center is at $5 \pm 0.1 \mu \mathrm{m}$. The traces in Figs. 3(a) and 3(b) are essentially flat and featureless except near the gap, where the largest negative frequency shift 




FIG. 3. Line traces taken horizontally across the center of the head, with head biases shown: (a) $\mathrm{Fe}_{70}\left(\mathrm{SiO}_{2}\right)_{30}$ tip; (b) $\mathrm{Fe}_{60}\left(\mathrm{SiO}_{2}\right)_{40}$ tip; and (c) $\mathrm{Co}_{85} \mathrm{Cr}_{15}$ tip previously magnetized to saturation along the tip axis. The gap is located at $5 \mu \mathrm{m}$. Arbitrary offsets were used to display the traces. The bottom three traces in (c) have been reduced by $50 \%(\times 0.5)$.

$\left(\Delta f_{\max }\right)$ occurs. The frequency shifts are primarily negative denoting an attractive tip-sample force, as expected for a soft tip. The response of both $\mathrm{Fe}-\left(\mathrm{SiO}_{2}\right)$ tips near the gap increases with increasing current bias and saturates at roughly $4 \mathrm{~mA}$ bias, in agreement with the manufacturer's specifications of the head. There is no detectable spatial shift of $\Delta f_{\max }$ at different current biases. Also expected for magnetically soft tips, the scans are identical for opposite current polarity as illustrated by the $\pm 10 \mathrm{~mA}$ traces. There is a small feature at $\sim 9 \mu \mathrm{m}$ corresponding to the fringing field on the outside of the P1 pole piece. The smaller features in Fig. 3(b) are due to topography and interface effects in the optical detection. All traces in Figs. 3(a) and 3(b) were reproducible, demonstrating the absence of tip memory effects with the $\mathrm{Fe}-\left(\mathrm{SiO}_{2}\right)$-coated tips. We also imaged bits on longitudinal hard disk media with the $\mathrm{Fe}_{70}\left(\mathrm{SiO}_{2}\right)_{30}$ tips and found that opposite polarity transitions gave equal response. The sensitivity of the $\mathrm{Fe}_{60}\left(\mathrm{SiO}_{2}\right)_{40}$ tips was not high enough to image these bits.

Figure 3(c) is illustrative of a CoCr tip while imaging an energized head whose peak field exceeds $H_{c}$ of the tip coating. After magnetizing the tip as for Fig. 2(d), the second through sixth traces were taken in the order they appear, top to bottom. Finally, the top trace was taken. The two traces at the same current bias of $+1.5 \mathrm{~mA}$ are not identical due to hysteresis of the tip moment. Traces of opposite current polarity $( \pm 1.5$ and $\pm 10 \mathrm{~mA})$ are neither identical nor show odd symmetry with respect to the gap. This lack of symmetry along with the predominantly attractive tip-sample response near the gap at higher current biases suggest that the $\mathrm{CoCr}$ tip response has both magnetically hard and soft components. This dual nature of the tip makes it difficult to determine important properties of the recording head such as the precise position of the center of the gap, the relative write field strengths at various current biases, and the symmetry of the field near the gap. For example, there is a spatial shift of $0.2 \mu \mathrm{m}$ for $\Delta f_{\max }$ for the second and third traces $( \pm 1.5 \mathrm{~mA})$ in Fig. 3(c), a shift comparable to the width of the gap. Differences between prior and subsequent MFM images of bits on a hard disk confirmed that the tip moment $\mathbf{m}$ was changed (written) by the write head.

Figure 3 shows that the tip response to the gap field is spatially the narrowest for the $\mathrm{Fe}_{70}\left(\mathrm{SiO}_{2}\right)_{30}$ tip. We can quantify this from the line traces by measuring the full width at half-maximum (FWHM). At +2 and $+10 \mathrm{~mA}$ biases we measure the FWHM for the $\mathrm{Fe}_{70}\left(\mathrm{SiO}_{2}\right)_{30}$ tip to be roughly 430 and $500 \mathrm{~nm}$, for the $\mathrm{Fe}_{60}\left(\mathrm{SiO}_{2}\right)_{40}$ tip 580 and $600 \mathrm{~nm}$, and for the CoCr tip 500 and $600 \mathrm{~nm}$, respectively.

As mentioned above, the presence of magnetic forces can cause an error in the topographical force image and requires that a correction be made to obtain the true tipsample spacing for the magnetic image. By subtracting the topography of the unbiased head from the image taken at $+10 \mathrm{~mA}$ bias, we found a maximum correction near the gap of approximately $+2,+1$, and $+30 \mathrm{~nm}$ for the $\mathrm{Fe}_{70}\left(\mathrm{SiO}_{2}\right)_{30}$, $\mathrm{Fe}_{60}\left(\mathrm{SiO}_{2}\right)_{40}$, and $\mathrm{CoCr}$ tips used in Figs. 2 and 3. This correction for the $\mathrm{CoCr}$ tip is substantially larger than the true topographical features and is approaching the intended 100 $\mathrm{nm}$ tip-sample spacing for the MFM image.

In conclusion, MFM images taken with $\mathrm{Fe}_{70}\left(\mathrm{SiO}_{2}\right)_{30}$ and $\mathrm{Fe}_{60}\left(\mathrm{SiO}_{2}\right)_{40}$-coated tips show substantially reduced tip moment hysteresis effects compared to images taken with $\mathrm{Co}_{85} \mathrm{Cr}_{15}$-coated tips. Given the signal-to-noise ratio of existing commercial MFMs, the higher sensitivity of the $\mathrm{Fe}_{70}\left(\mathrm{SiO}_{2}\right)_{30}$ tips makes them more appropriate than the $\mathrm{Fe}_{60}\left(\mathrm{SiO}_{2}\right)_{40}$ tips for imaging the write field above heads. These tips should also be useful for imaging permanent magnet materials and very high-coercivity media. Optimization of the Fe particle size, size uniformity, and interparticle separation in the nonmagnetic $\mathrm{SiO}_{2}$ matrix should produce films that have improved superparamagnetic properties. This will allow thinner coatings with higher $\mathrm{Fe}$ concentrations on sharper tips, with the goal of simultaneously improving sensitivity and resolution.

We thank P. Rice, R. E. Thomson, and K. Babcock for advice. The work at the University of Nebraska was supported by NSF Grant No. OSR-9255225.

${ }^{1}$ P. Grütter, D. Rugar, H. J. Mamin, G. Castillo, S. E. Lambert, C.-J. Lin, R. M. Valletta, O. Wolter, T. Bayer, and J. Greschner, App. Phys. Lett. 57, 1820 (1990).

${ }^{2}$ K. Babcock, V. Elings, M. Dugas, and S. Loper, IEEE Trans. Magn. 30, 4503 (1994).

${ }^{3}$ See, for example, P. Grütter, H. J. Mamin, and D. Rugar, in Scanning Tunneling Microscopy II, edited by R. Wiesendanger and H.-J. Güntherodt (Springer, Berlin, 1992), pp. 151-207.

${ }^{4}$ K. Babcock, M. Dugas, S. Manalis, and V. Elings, in Proceedings of the Material Research Society Meeting, edited by Demczyk et al. [Mater. Res. Soc. Symp. Proc. 355, 311 (1995)].

${ }^{5}$ H. J. Mamin, D. Rugar, J. E. Stern, R. E. Fontana, Jr., and P. Kasiraj, Appl. Phys. Lett. 55, 318 (1989).

${ }^{6}$ S. H. Liou and C. L. Chien, J. Appl. Phys. 63, 4240 (1988); C. L. Chien, G. Xiao, S. H. Liou, J. N. Taylor, and A. Levy, ibid. 61, 3311 (1987).

${ }^{7}$ Y. Kanai and S. H. Charap, J. Appl. Phys. 69, 4478 (1991).

${ }^{8}$ S. S. Malhotra, Y. Liu, J. X. Shen, S. H. Liou, and D. J. Sellmyer, J. Appl. Phys. 76, 6304 (1994).

${ }^{9}$ V. Elings and J. Gurley, U.S. Patent Nos. 5,266, 801 and 5,308,974. 